Research Article

\title{
Fluctuation Characteristic Test of Oblique Stress Waves in Infilled Jointed Rock and Study of the Analytic Method
}

\author{
Jin Yu $\mathbb{D}^{1}{ }^{1}$ Zehan Liu $\mathbb{D}^{1}{ }^{1}$ Ze He, ${ }^{1}$ Xianqi Zhou, ${ }^{1,2}$ and Jinbi Ye ${ }^{2}$ \\ ${ }^{1}$ Fujian Research Center for Tunneling and Urban Underground Space Engineering, Huaqiao University, Xiamen, \\ Fujian 361021, China \\ ${ }^{2}$ School of Civil Engineering and Architecture, Xiamen University of Technology, Xiamen, Fujian 361021, China \\ Correspondence should be addressed to Jin Yu; bugyu0717@163.com
}

Received 22 July 2019; Revised 29 October 2019; Accepted 21 December 2019; Published 11 January 2020

Academic Editor: Eric Lui

Copyright (C) 2020 Jin Yu et al. This is an open access article distributed under the Creative Commons Attribution License, which permits unrestricted use, distribution, and reproduction in any medium, provided the original work is properly cited.

\begin{abstract}
The propagation of stress waves in filled jointed rocks involves two important influencing factors: transmission-reflection phenomena and energy attenuation. In this paper, the split Hopkinson pressure bar (SHPB) test is used to shock the filled rock with joint angles of 0,30 , and $45^{\circ}$ and the thickness of $4 \mathrm{~mm}$ and $10 \mathrm{~mm}$, respectively, in three different velocities. The wave curves of the incident wave, reflected wave, and transmission are obtained. The effects of the filling angle and joint thickness on wave propagation are analyzed. Based on the propagation characteristics of stress waves in joints, the stress expression of oblique incident stress waves propagating in filling joints is derived, and the energy coefficient of transmission and reflection is calculated. The results show that the propagation of stress wave in filling joints is related to the impact rate. The larger the impact rate is, the larger the maximum voltage amplitude of the three waves is. And the increasing amplitude of the incident and reflected waves is larger than the transmitted wave; the greater the impact velocity is, the smaller the stress-strain curve gap of the three dip joints is, and the fracture strength of the specimen decreases with the increase of the joint dip angle. The larger the joint dip angle is, the smaller the deformation of the rock-like specimen is. The change of the transmission coefficient is related to the joint angle, and the larger joint angle weakens the influence of the joint width on the transmission of the transmitted wave; under each impact velocity, the theoretical and experimental stress peaks are approximately the same, and the transmission coefficient maintains a good consistency with the oblique incident angle.
\end{abstract}

\section{Introduction}

Rock is a natural geological body formed by the aggregation of minerals or cuttings under geological conditions. It is an important part of rock mass. The interior of the rock mass retains various permanent deformations and various geological structural traces such as unconformity, folds, and joints. The existence of joints can result in the discontinuity, heterogeneity, and anisotropy of rock mass. Moreover, the propagation of stress waves in the jointed rock mass can become a complicated process. Stress wave attenuation occurs when the joint filling reaches a certain thickness and becomes nonnegligible. In addition, it can cause the attenuation of wave propagation velocity and energy which can further affect the stability of rock mass [1-3]. The incidence condition of stress waves at any angle can be more complicated than that of the vertical incidence condition in the rock joint. Therefore, profoundly studying the fluctuation characteristics and the dynamic properties of stress waves in the infilled obliquely jointed rock mass will have considerable theoretical significance and engineering application value.

The dynamic mechanical response of an infilled joint and its influence on the propagation characteristics of stress waves after an oblique incidence have become a hotspot research topic. Numerous researchers have investigated infilled jointed rock masses from theoretical and experimental aspects. Zhou et al. [4] used the professional finite difference software FLAC3D to carry out complex modeling and numerical simulation of embankment stability of tunnel blasting force to reveal the relationship between the blasting seismic wave and vibration velocity and embankment 
displacement under different excavation steps. However, the effect of joints on blasting seismic waves has not been analyzed in the greater depth. Indraratna et al. $[5,6]$ and $\mathrm{Yu}$ et al. [7] studied the peak shear strength of jointed rock mass with soft fillings. Khosravi et al. [8] used cylindrical plaster cast specimens containing oblique zigzag infilled joints to study the hydraulic fracture mechanism of infilled joints. Mirzaghorbanali et al. [9] used clay-sand-filled model specimens to conduct a cyclic shear test under normal stiffness, based on which a mathematical model was proposed to evaluate the shear strength of infilled joints under the effect of cyclic shear load. Chen et al. $[10,11]$ studied the influences of joint goodness-of-fit on the joint transmission coefficient and the joint stiffness by grooving on a rock without considering the oblique incidence of stress waves. $\mathrm{Li}$ et al. [12-14] combined wavefront momentum conservation theory and a displacement discontinuity method to propose a recursive analysis method of time domain in the stress wave propagation process. In addition, the authors carried out an experimental study of the propagation characteristics of stress waves in infilled joints under the impact load through the split Hopkinson pressure bar (SHPB). However, the energy attenuation brought by the thickness of the infilled joint to the stress wave propagation was not considered. Li et al. [15] used the split Hopkinson pressure bar to study the influence of joint thickness on seismic response across a filled fracture with strong nonlinear deformability. However, the influence of joint angles was not considered. Yang et al. [16] conducted an impact test of jointed rock specimens, which were manually fabricated, through the SHPB device and explored the influence of joint filling on the dynamic mechanical properties of rocks. However, the authors' study was only restricted to conditions under a 0 dip angle of joints, whereas the influence of other joint angles on stress wave propagation was neglected. Li and Ma [17] established the propagation equation of explosive stress waves after an oblique incidence into linear elastic joints according to the law of momentum conservation on the wavefront and displacement discontinuity at the two sides of the infilled joints. Moreover, the authors obtained the analytical expression of the transmission and reflection coefficients of the stress waves propagated on the joint surface. Che et al. [18] investigated the influence of stress waves on the slope stability of a jointed rock mass through a numerical simulation and an experimental study. However, the influence of the joint width on stress wave propagation was not considered, and the attenuation phenomenon of stress wave transmission was neglected.

Specimens containing oblique joints are fabricated for the SHPB test to study the wave laws of oblique stress waves in the infilled jointed rock with certain thickness. Vertical impact is used to reflect the oblique incidence, and the incident, reflected, and transmissive waveforms before and after the stress waves that traverse the joint are obtained. In addition, the influences of the joint angle and thickness on stress wave propagation are analyzed. Moreover, the stress expression regarding the propagation of oblique stress waves in the infilled joint is derived. Then, the transmission and reflection energy coefficients are calculated and compared with the test values. Finally, the related conclusions are obtained. These findings could have a guiding importance on the analysis of the propagation of oblique stress waves in the infilled joint as well as on complicated engineering calculations.

\section{Testing Program Design and Specimen Preparation}

2.1. Program Design. Three joint angles, namely, $0^{\circ}, 30^{\circ}$, and $45^{\circ}$, were designed to investigate the influence of different joint angles on wave propagation characteristics [7, 19]. All the joints ran through the specimen along the axial direction, and the joint thicknesses were $4 \mathrm{~mm}$ and $10 \mathrm{~mm}$. The draw ratio of each specimen was $1 / \varnothing=1$. Given that the diameter of the incident SHPB was $50 \mathrm{~mm}$, the specimen diameter and height were the same at $50 \mathrm{~mm}$. The specimens were fabricated by using a manual preparation method, and the specimen design is shown in Figure 1.

The impact velocity of the SHPB in the test was decided by the air pressure and the distance from the impact bar to the incident bar. Three different impact conditions were designed in the test, and the distance from the impact bar to the incident bar was strictly controlled. Meanwhile, the air pressure threshold $P$ was set, and the distance from the impact bar to the incident bar was set as $L$. They are $P_{1}=0.1 \mathrm{MPa}$, $L_{1}=25 \mathrm{~cm}, P_{2}=0.1 \mathrm{MPa}, L_{2}=40 \mathrm{~cm}, P_{3}=0.2 \mathrm{MPa}$, and $L_{3}=30 \mathrm{~cm}$. The mean values of the three impact velocities measured through the experiment were as follows: $V_{1}=3.26 \mathrm{~m} / \mathrm{s}, V_{2}=4.11 \mathrm{~m} / \mathrm{s}$, and $V_{3}=5.53 \mathrm{~m} / \mathrm{s}$.

2.2. Specimen Preparation. A natural jointed rock mass is a composite structure consisting of a rock and a structural plane (layer) containing fillings. Similarity theory and domestic and foreign rock specimen preparation experience [20] were combined, in the manual specimen preparation process. Cement mortar was selected as the specimen material, simulation was conducted by regulating different matching ratios of the cement mortar [16], and the concrete matching ratio of the cement mortar and the mechanical parameters is shown in Table 1.

A cylinder model was prepared. The die was a transparent PVC tube with $50 \mathrm{~mm}$ inner diameter, $5 \mathrm{~mm}$ thickness, and $50 \mathrm{~mm}$ height. One of its ends was sealed. During the specimen preparation process, hand mixing and vibrating modes were adopted after intensive mixing according to the matching ratio of the cement mortar in Table 1. The specimen contained infilled joints, and the layered casting mode was adopted. The purpose of controlling the thickness of the joint layer is achieved by controlling the quality of the mortar. The angle of joint layer can be controlled by controlling the distance between joint boundary and specimen boundary. Given that the oblique joint and angle were involved, accuracy control was required. Meanwhile, the complete rock specimen was cast according to the matching ratio as the blank control. After casting was completed, it was cured in a curing tank for 28 days. It was removed and dried after curing, and the PVC 

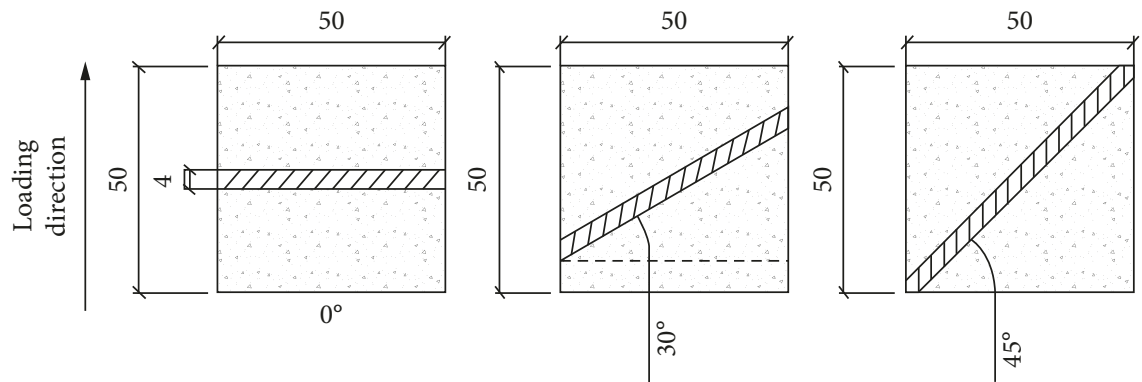

(a)
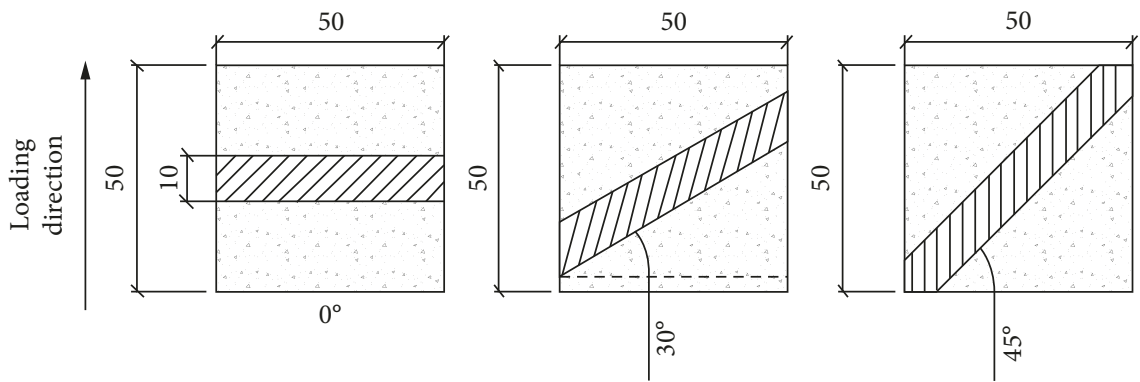

(b)

Figure 1: The design figure of two thickness filler joint test pieces: (a) $4 \mathrm{~mm}$ and (b) $10 \mathrm{~mm}$.

TABLE 1: Mechanical parameters of the simulated rock and joint.

\begin{tabular}{|c|c|c|c|c|}
\hline \multirow{2}{*}{ Material category } & \multirow{2}{*}{ Mortar ratio } & \multicolumn{3}{|c|}{ Parameter } \\
\hline & & Density $\left(\mathrm{g} \cdot \mathrm{cm}^{-3}\right)$ & Elastic modulus (GPa) & Poisson's ratio $(v)$ \\
\hline Rock & $20: 40: 9$ & 2.08 & 31.3 & 0.25 \\
\hline Joint & $20: 60: 11$ & 1.86 & 26.5 & 0.32 \\
\hline
\end{tabular}

The proportion of mortar is cement: sand: water: cement is marked with 42.5 cement; fine sand is made of river sand with a particle size of $0.5 \mathrm{~mm} \sim 1 \mathrm{~mm}$.

tube was cut open by a cutting machine to remove the specimen. The sample is shown in Figure 2.

2.3. Testing and Loading Equipment. A right conical and variable cross-sectional SHPB device was used in the test, and the system satisfied the hypothesis of $1 \mathrm{D}$ plane stress conditions [21]. A circular brass sheet was selected in the test as a wave shaper to improve the waveform distortion and the nonuniform stress. The images of the testing device and the schematic of its working principle are shown in Figure 3.

The specimen was placed between the incident and the transmission bars, and then the impact bar was driven by the impact wave, which was released by the compressed gas. The specimen experienced a reflection and transmission phenomenon on the contact face between itself and the bar when the impact wave passed through it. The initial positions of the impact and incident bars remained unchanged in the test to obtain the same impact velocity. The infilled jointed specimen was included between the incident and transmission bars. Vaseline was evenly smeared on the contact face between the specimen and the steel rod to reduce friction. The stress wave generator was started to allow the impact bar to influence the elastic incident bar, thereby generating a loaded stress wave of a certain shape. The time the impact bar spent in passing through the UV receiver was directly measured by using a velocimeter, and the impact velocity in the test process was calculated. Each test was repeated thrice to ensure the accuracy of the test results.

\section{Test Results and Analysis}

3.1. Stress Wave Oscillograph Measured in the Test. The incident, transmissive, and reflected waves were measured through strain gauges on the incident and transmission bars. The specimens with $4 \mathrm{~mm}$ and $10 \mathrm{~mm}$ joint thicknesses had similar laws. Thus, the $4 \mathrm{~mm}$ thickness was taken as an example in the analysis process to avoid unnecessary details.

Figure 4 shows the impact process morphology of complete rock specimens and the $4 \mathrm{~mm}$ filled joint specimens with different impact velocities at the same oblique incidence angle. The maximum voltage amplitudes of the incident, reflected, and transmissive waves of the complete rock specimen were greater than those of the jointed specimen. Figures 4(a)-4(c) show that when the jointed specimens with different angles were impacted under velocities $V_{1}$ and $V_{2}$, the maximum voltage amplitudes $U_{\text {Imax }}$ and $U_{\mathrm{Rmax}}$ of the incident and reflected waves presented a gradually increasing trend as the dip angle declined. Both values were smaller than $0.6 \mathrm{~V}$. $U_{\text {Tmax }}$ of the transmissive 


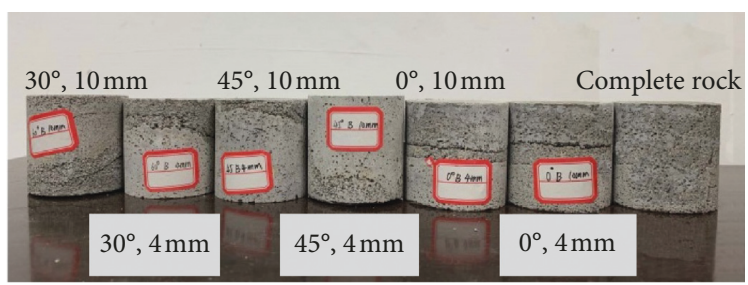

(a)

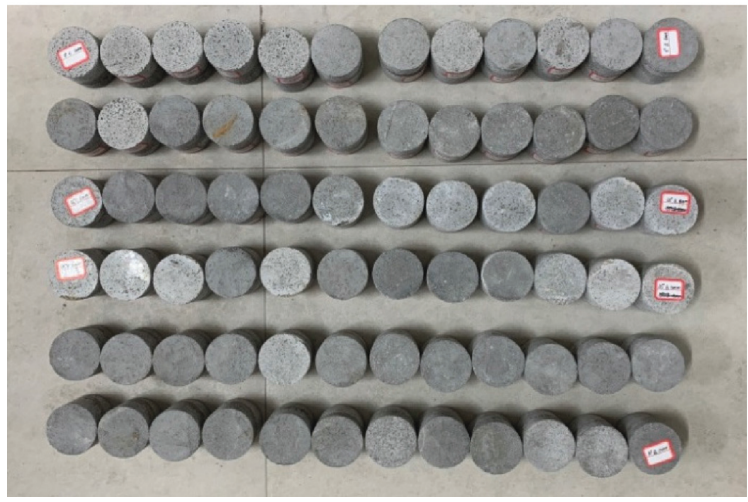

(b)

FIgURE 2: Shape after processing the specimen.
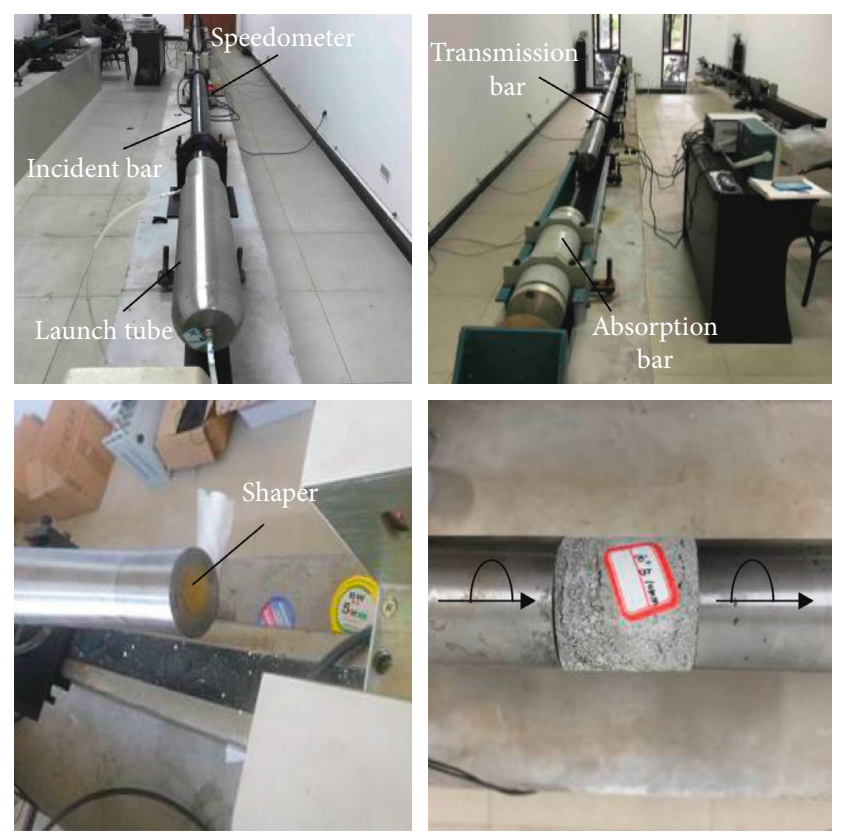

Figure 3: Test device of SHPB.

wave also presented similar laws. The transmissive wave was triggered after the reflected wave started, and $U_{\text {Tmax }}$ fluctuated at $0.2 \mathrm{~V}$. When the jointed specimens with different angles were impacted under velocity $V_{3}$, the maximum voltage amplitudes of the incident wave and reflected waves were evidently elevated, thereby reaching approximately $0.9 \mathrm{~V}$.

Figure 5 shows the failure modes of the specimens under the impact velocity (the joint angles of the specimens were $45^{\circ}, 30^{\circ}$, and $0^{\circ}$ in Figures $5(\mathrm{a})-5(\mathrm{c})$, and Figure 5(d) shows the complete specimens without joints).

Figure 5 reveals that all the infilled jointed specimens experienced evident macroscopic failure under the impact velocity of $V_{3}$. However, the specimens had slightly different failure modes under different joint angles. The joint-free complete rock had a similar failure mode to that under the joint angle. In other words, the specimen which was contacted with the end of the incident bar and the joint was fractured, while the other end remains relatively intact. The infilled jointed specimen fractured into multiple blocks when the joint angle was $30^{\circ}$. The infilled jointed specimen fractured into fine blocks when the joint angle was $45^{\circ}$. Figure 6 presents the changed laws of the maximum voltage amplitude of the infilled jointed specimen with $4 \mathrm{~mm}$ thickness and a joint angle under three different impact velocities.

Figure 6 shows the following: (1) The maximum voltage amplitudes of the incident, reflected, and transmissive waves (hereinafter referred to as the three waves) presented identical declining trends with the joint angle. The descending slope of the maximum voltage amplitude from $0^{\circ}$ to $30^{\circ}$ was evidently smaller than that from $30^{\circ}$ to $45^{\circ}$. Thus, the maximum voltage amplitudes of the three waves presented declining trends with the joint angle. Moreover, the larger the joint angle, the more evident the declining trend of the maximum voltage amplitude. This conclusion was consistent with the conclusion drawn by Yan et al. [22] in the experimental study of SHPB-like materials in the dynamic failure of jointed rocks. (2) When the joint angle was certain, the higher the impact velocity, the greater the maximum voltage amplitudes of the three waves. Furthermore, the higher the impact velocity, the faster the maximum voltage amplitudes of the incident and reflected waves. When the 


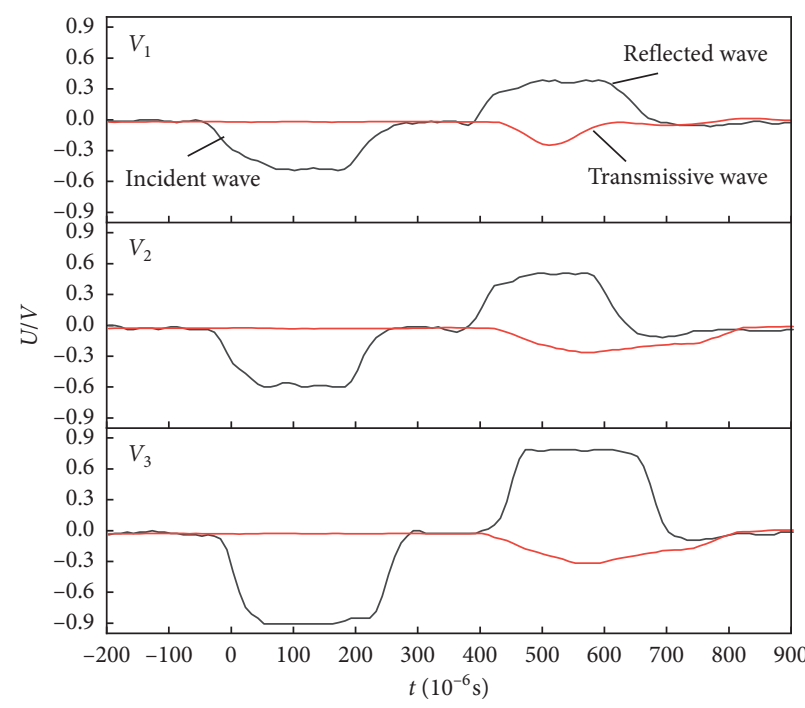

(a)

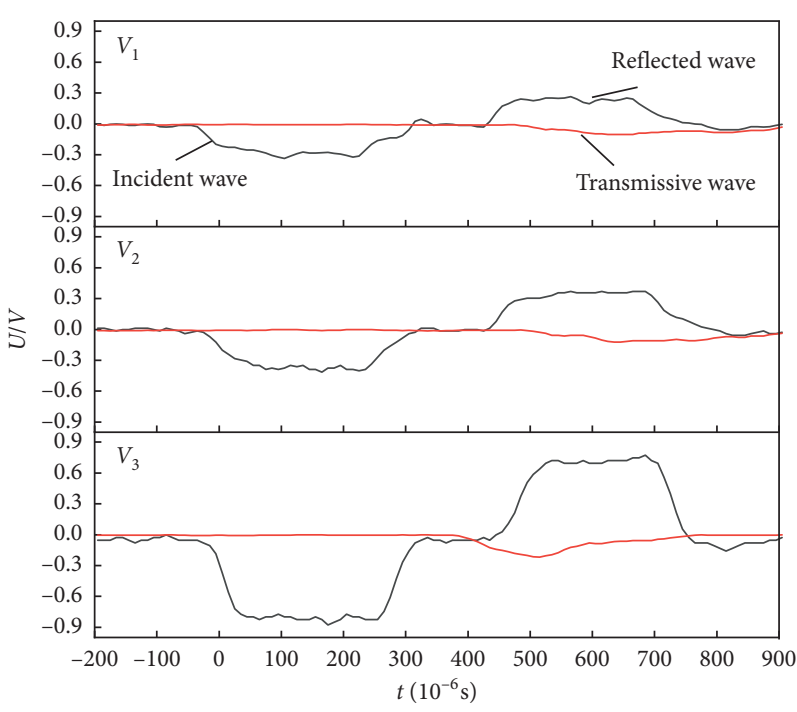

(c)

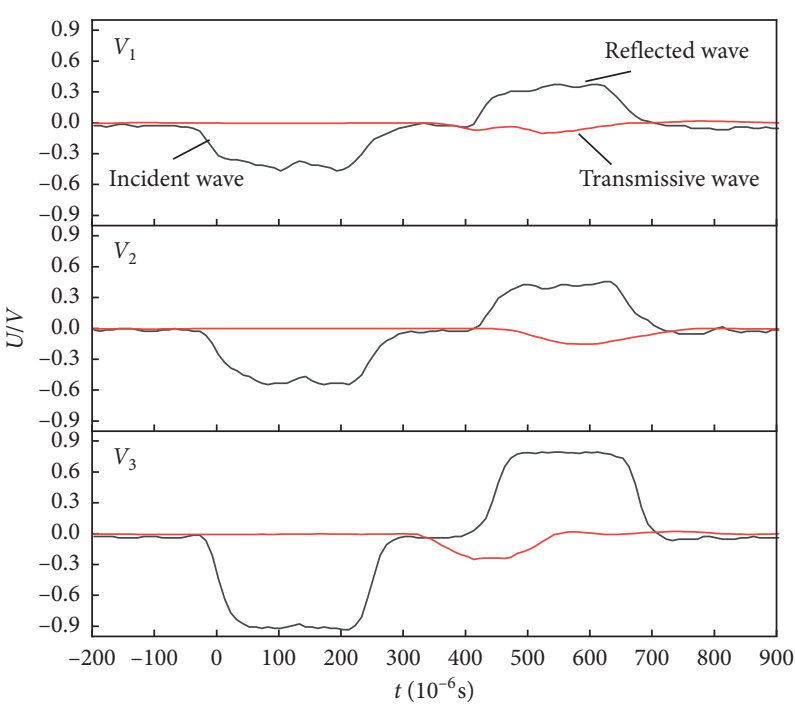

(b)

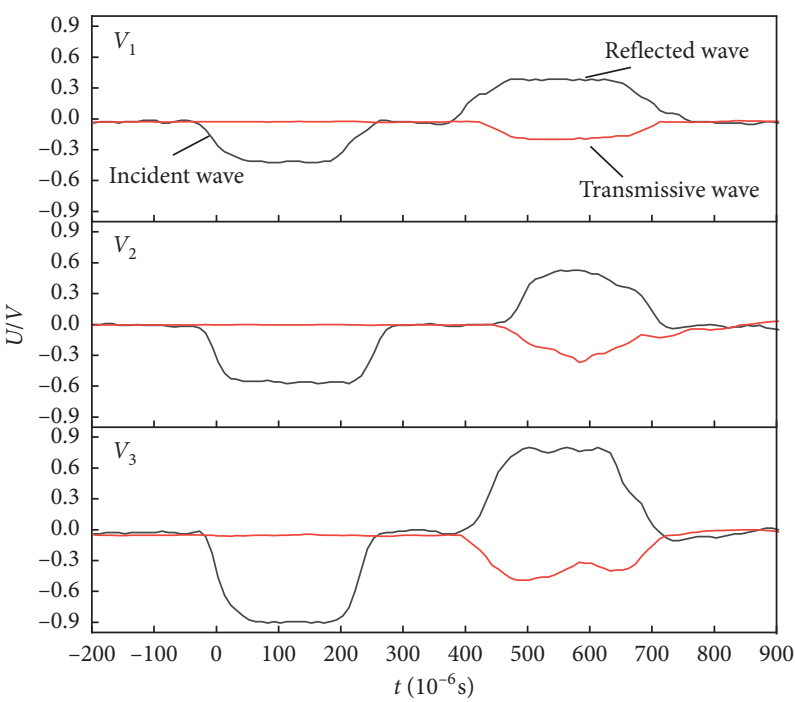

(d)

Figure 4: Morphology of $4 \mathrm{~mm}$ filled joint specimens under impact at different impact velocities. The shape of $0^{\circ}$ (a), $30^{\circ}$ (b), $45^{\circ}$ (c), and unjointed (d) rock mass specimens under different impact velocities.

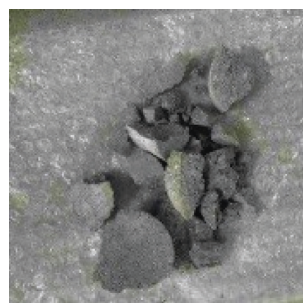

(a)

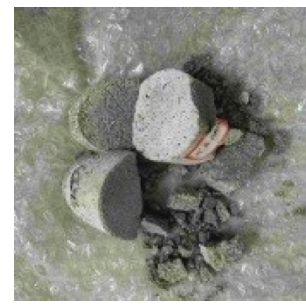

(b)

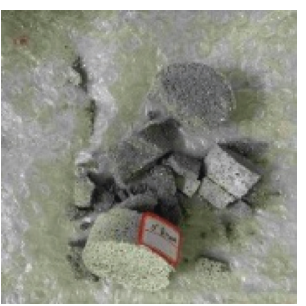

(c)

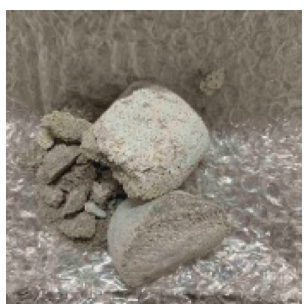

(d)

FIgURE 5: Damage form of $4 \mathrm{~mm}$ specimens under impact velocity $V_{3}$ : (a) $\theta=45^{\circ}$, (b) $\theta=30^{\circ}$, (c) $\theta=0^{\circ}$, and (d) no joint.

impact velocity increased from $V_{1}$ to $V_{2}$, the increase in the maximum voltage amplitudes of the three waves were small. However, when the impact velocity increased from $V_{2}$ to $V_{3}$,
$U_{\max }$ of the incident and reflected waves rapidly increased to $0.9 \mathrm{~V}$, whereas the growth of the transmissive wave was not evident. 


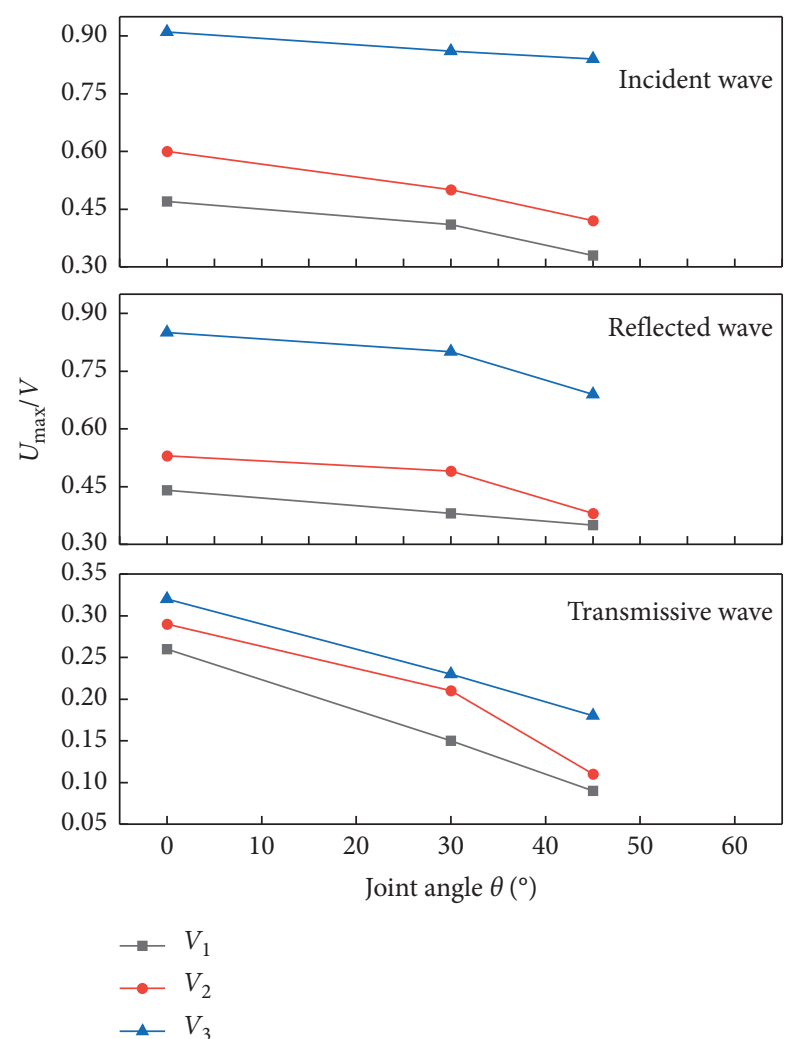

FIgURE 6: The variation of $U_{\max }$ with the joint angle of the filled joint sample.

3.2. Rock Stress-Strain Relation Analysis. Figure 7 shows the dynamic stress-strain curves of infilled jointed specimens with $4 \mathrm{~mm}$ thickness and different angles, which were measured under three different impact velocities. Figures 7(a)-7(c) represent the stress-strain relation curves under impact velocities $V_{1}, V_{2}$, and $V_{3}$, respectively.

As shown in Figure 7 , the gaps of the stress-strain curves of joints with three dip angles were gradually diminished as the impact velocity rose. The larger the joint angle $\theta$, the lower the peak stress of the rock specimen; that is, the failure strength of the specimen decreased as the joint angle $\theta$ increased. The larger the joint angle, the smaller the deformation of the rock specimen; that is, the specimen deformation decreased as the joint angle $\theta$ increased. Figure 7 (a) shows that under a low-impact velocity $V_{1}$, the stress-stain curves of $30^{\circ}$ and $45^{\circ}$ joint angles were approximate. Evident linear elastic deformation features appeared in the initial phase, followed by the unstable fracture development phase. When the stress reached approximately 55-65 $\mathrm{MPa}$, the specimen entered the postfailure phase, and the curve change was major under the joint angle $0^{\circ}$, with an evident strengthening phenomenon. When the stress reached $75 \mathrm{MPa}$, the specimen entered the postfailure phase, and the peak stress of the specimen gradually declined as the joint angle $\theta$ increased. Figures 7 (b) and $7(\mathrm{c})$ also reflect similar laws, thereby indicating that the change in joint angle $\theta$ considerably affected the dynamic mechanical properties of rock-like specimens.
Table 2 shows the basic test parameters of different infilled joints under a high-impact velocity $V_{3}$ and the test results under the effect of dynamic load. Table 2 indicates that the peak stress of each specimen presented a rising trend with the impact velocity. When impact velocity was $V_{1}$, the average peak stress was $61 \mathrm{MPa}$. The average peak stress was $112 \mathrm{MPa}$ when the impact velocity increased to $V_{3}$. When the average impact velocity was $V_{1}=3.37 \mathrm{~m} \cdot \mathrm{s}^{-1}$, the variance value of the peak stresses was 8.75 . The variance value of the peak stresses was 9.48 under $V_{2}=4.14 \mathrm{~m} \cdot \mathrm{s}^{-1}$ and 5.41 under $V_{3}=5.61 \mathrm{~m} \cdot \mathrm{s}^{-1}$. Thus, the higher impact velocity, the smaller the discreteness of the peak stress.

3.3. Energy Analysis. Therefore, the test conditions satisfied the $1 \mathrm{D}$ assumptions of the SHPB principle. The stress wave was a $1 \mathrm{D}$ elastic longitudinal wave and did not experience stress attenuation when propagated along the incident and transmission bars. According to the energy calculation formula of the SHPB, the incident, reflected, and transmissive energies are expressed as follows:

$$
\left\{\begin{array}{l}
W_{\mathrm{I}}(t)=A_{0} E_{1} C_{1} \int_{0}^{t} \varepsilon_{I}(t) \mathrm{d} t \\
W_{\mathrm{R}}(t)=A_{0} E_{1} C_{1} \int_{0}^{t} \varepsilon_{R}(t) \mathrm{d} t \\
W_{\mathrm{T}}(t)=A_{0} E_{2} C_{2} \int_{0}^{t} \varepsilon_{T}(t) \mathrm{d} t
\end{array}\right.
$$

where $W_{\mathrm{I}}(t), W_{\mathrm{R}}(t)$, and $W_{\mathrm{T}}(t)$ are the energies of the incident, reflected, and transmissive waves, respectively; $\varepsilon_{I}(t), \varepsilon_{R}(t)$, and $\varepsilon_{T}(t)$ correspond to the strain time-history curve of the incident, reflected, and transmissive waves, respectively; $A_{0}$ is the sectional area of the compression bar; $E_{1}$ and $E_{2}$ are the elasticity modulus of the input and output bars, respectively; and $C_{1}$ and $C_{2}$ are the wave propagation velocities.

The law of energy conservation indicated that the energy $W_{\mathrm{S}}(t)$ absorbed by the specimen in the crushing process is as follows:

$$
W_{\mathrm{S}}(t)=W_{\mathrm{I}}(t)-W_{\mathrm{R}}(t)-W_{\mathrm{T}}(t)
$$

The consistency of the impact velocity under the same conditions could not be guaranteed given that the impact velocity was controlled by air pressure. To eliminate the influence of the amplitude fluctuation of the incident wave, the ratio method was used for the comparative analysis. Moreover, the average values of the data obtained through the same type of specimen were considered. Transmission coefficient $T$ was defined to quantitatively analyze the influence of joints on stress wave propagation, and its calculation formula is as follows:

$$
T=\frac{W_{\mathrm{T}}(t)}{W_{\mathrm{I}}(t)} .
$$

Statistical data were obtained according to the energy calculation formula of the SHPB, as shown in Table 3 . Energies and energy consumption ratios were obtained according to Table 3 when the stress waves passed through 


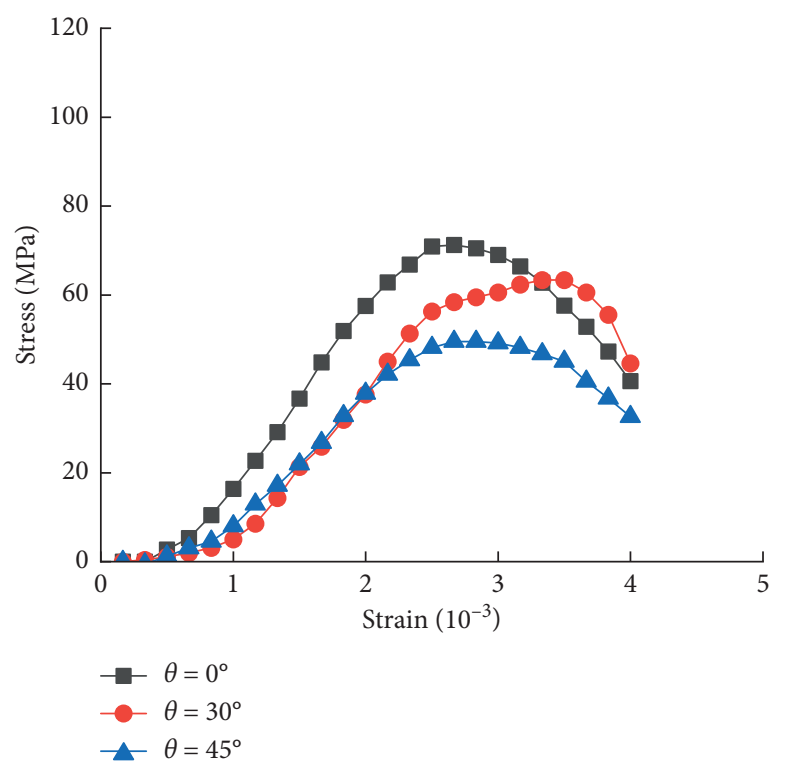

(a)

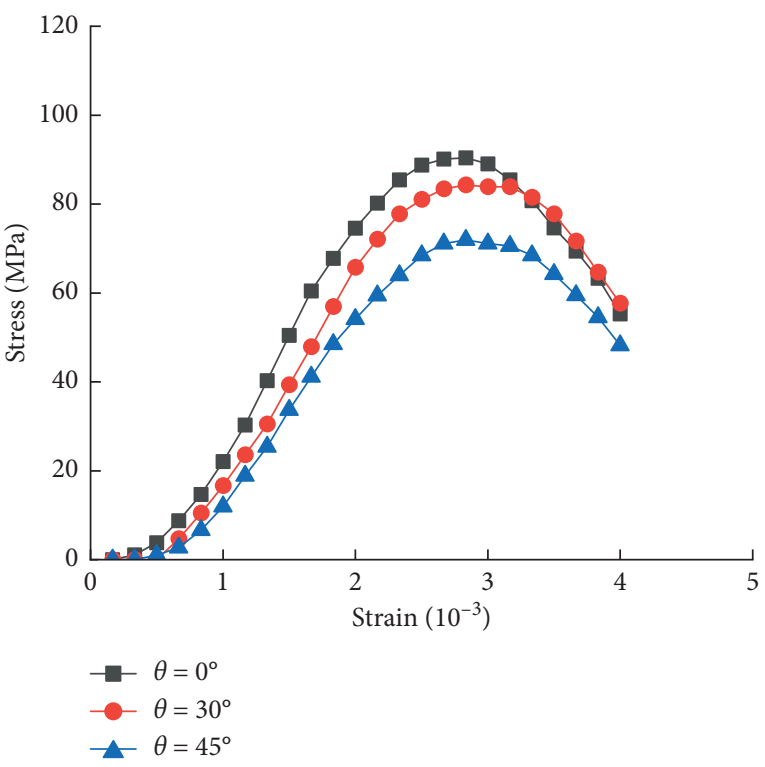

(b)

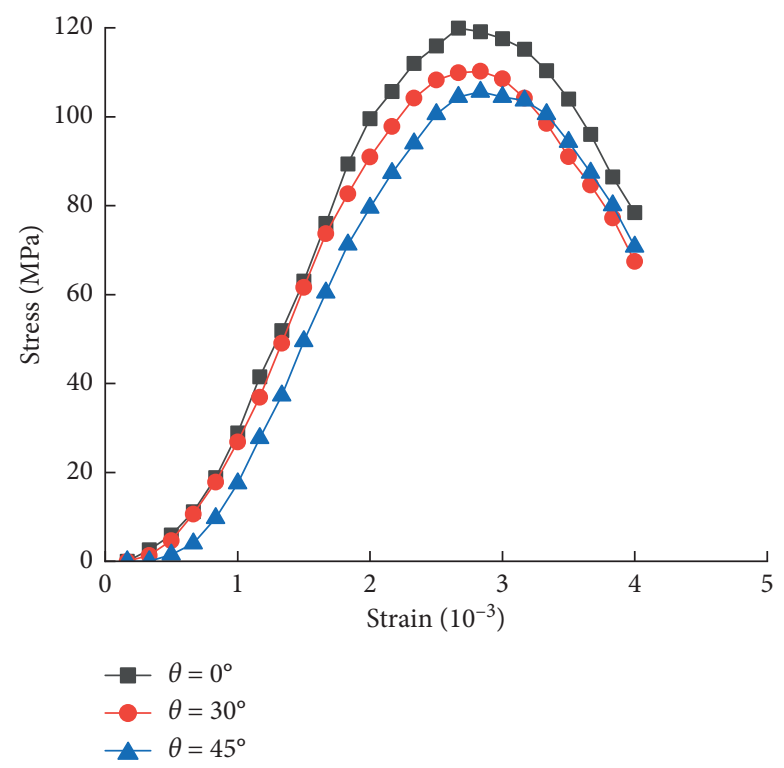

(c)

FiguRE 7: Stress-strain relation curves of different joints under three impact velocities: (a) $V_{1}$, (b) $V_{2}$, and (c) $V_{3}$.

TABle 2: Test results of test pieces under different joint materials.

\begin{tabular}{lcccc}
\hline \multirow{2}{*}{ Joint angle $\theta\left(^{\circ}\right)$} & \multicolumn{2}{c}{ Impact velocity $\left(\mathrm{m} \cdot \mathrm{s}^{-1}\right)$} & \multicolumn{2}{c}{ Stress peak $(\mathrm{MPa})$} \\
Average value & Test value & Average value \\
\hline 0 & 3.30 & 3.37 & 71 & 61 \\
30 & 3.57 & & 63 & 0.00267 \\
45 & 3.25 & & 50 & 0.00351 \\
\hline 0 & 4.16 & 4.14 & 90 & 0.00282 \\
30 & 4.30 & & 84 & 000284 \\
45 & 3.97 & & 72 & 0.00252 \\
0 & 5.73 & 5.61 & 120 & 0.00285 \\
30 & 5.70 & & 110 & 0.00323 \\
45 & 5.40 & & 106 & 0.00338 \\
\hline
\end{tabular}


the rock specimens with different joint angles under three different impact velocities. The specimen contained discontinuous structural planes owing to the existence of joints. When a longitudinal wave generated under the impact load was propagated in the specimen, the stress wave passed through transmission and reflection, thereby generating amplitude attenuation and energy dissipation. Thus, the transmission coefficient was smaller than 1 .

Figure 8 shows the change curves of the average transmission coefficient and the joint angle of the same type of specimens under different joint thickness values and three different impact velocities.

As shown in Figure 8, when the joint width was certain, the average transmission coefficient presented a declining trend as the joint angle increased under different impact velocities. Moreover, the larger the angle, the more evident the declining trend. Under the same impact velocity, the smaller the joint angle, the smaller the wave attenuation, and the larger the amplitude of the transmissive wave. When the incident wave was propagated in the specimen with a $4 \mathrm{~mm}$ joint width, its transmissivity was evidently better than the specimen with a $10 \mathrm{~mm}$ joint width. In addition, as the joint angle increased, the difference between the two specimens with different joint widths was gradually reduced, declining from $3.45 \%$ under $\theta=0^{\circ}$ to $3.11 \%$ under $\theta=45^{\circ}$. Thus, the large joint angle weakened the influence of the joint width on the transmissive wave propagation. The stiffness of the joint material was lower than that of the rock material. The greater the joint width, the smaller the overall specimen stiffness. Then, the transmission coefficient under a small joint width and tight distribution was larger than that under a large joint width and discrete distribution [20].

Different impact velocities would cause different incident wave energies and different displacements generated by the joint, which would also impact stress wave propagation. Figure 9 shows the change curves of the transmission coefficients of infilled joints under three different impact velocities. The figure demonstrates that when the joint width was certain, the effect of the impact velocity on the transmission coefficient would be gradually weakened as the joint angle increased. When the joint width was $4 \mathrm{~mm}$, the variance value of the transmission coefficients under three impact velocities and the joint angle $\theta=0^{\circ}$ was 0.0165 and 0.0018 under $\theta=30^{\circ}$. The value declined to 0.0011 when the joint angle increased to $\theta=45^{\circ}$, and the joints with a $10 \mathrm{~mm}$ width had the same laws.

\section{Stress Attenuation in the Infilled Joint}

4.1. Stress Wave Transmission in the Infilled Joint. The transmission of oblique stress waves in the structural plane included the transmission from rock to infilled joint, from infilled joint to rock, and multiple transmission and reflection in the infilled joint. The transmission process can be expressed in Figure 10.

The longitudinal wave velocity in the rock mass was set as $C_{1}$, the longitudinal wave velocity of the filling medium in the joint was $C_{2}$, and $\rho_{1}$ and $\rho_{2}$ were the initial densities of the rock and the filling media, respectively. The characteristic impedances of the rock and the filling media in the joint were expressed by $\rho_{1} C_{1}$ and $\rho_{2} C_{2}$, respectively. When the stress wave experienced the first transmission and reflection on the interface under the angle of incidence $\theta$, the reflected wave $\sigma_{\mathrm{R}}$ and the transmissive wave $\sigma_{\mathrm{T}}$ can be written as follows:

$$
\left.\begin{array}{c}
\sigma_{\mathrm{R}}=\frac{\rho_{2} C_{2}-\rho_{1} C_{1}}{\rho_{2} C_{2}+\rho_{1} C_{1}} \sigma_{\mathrm{I}} \frac{\cos \theta}{\cos \beta_{\mathrm{R}}} \\
\sigma_{\mathrm{T}}=\frac{2 \rho_{2} C_{2}}{\rho_{2} C_{2}+\rho_{1} C_{1}} \sigma_{\mathrm{I}} \frac{\cos \theta}{\cos \alpha_{\mathrm{T}}}
\end{array}\right\},
$$

where $\sigma_{\mathrm{I}}, \sigma_{\mathrm{R}}$, and $\sigma_{\mathrm{T}}$ are the incident wave, reflected wave, and transmissive wave stresses, respectively; the angle of incidence is $\theta$; and $\beta_{\mathrm{R}}$ and $\alpha_{\mathrm{T}}$ are the angles of reflection and transmission after the incident wave went through the first transmission and reflection on the interface, respectively; and the remaining transmissions can be performed in the same manner.

When the transmissive wave $\sigma_{\mathrm{T}}$ reached the interface at the other size through the filling medium in the joint, as the stress wave attenuated with distance, $\sigma_{\mathrm{T}}$ was transformed into $\Delta \sigma_{\mathrm{T} 1}+\sigma_{\mathrm{T}}$, where $\Delta \sigma_{\mathrm{T} 1}$ was the increment of the effective width $\Delta r$ that passed by $\sigma_{\mathrm{T}}$ on the surface of the infilled joint (reduced to a negative value). $\Delta \sigma_{\mathrm{T} 1}+\sigma_{\mathrm{T}}$ would experience another reflection on this interface. The reflected wave was expressed by $\sigma_{\mathrm{R} 1}$, and then the following can be obtained:

$$
\sigma_{\mathrm{R} 1}=\frac{\rho_{1} C_{1}-\rho_{2} C_{2}}{\rho_{2} C_{2}+\rho_{1} C_{1}}\left(\Delta \sigma_{\mathrm{T} 1}+\sigma_{\mathrm{T}}\right) \frac{\cos \alpha_{\mathrm{T}}}{\cos \beta_{\mathrm{R} 1}} .
$$

For the convenience of the following calculation, $\Delta \sigma_{\mathrm{T} 1}=$ $\Delta \sigma_{1}$ was set, and equation (5) can be rewritten as follows:

$$
\sigma_{\mathrm{R} 1}=\frac{\rho_{1} C_{1}-\rho_{2} C_{2}}{\rho_{2} C_{2}+\rho_{1} C_{1}}\left(\Delta \sigma_{1}+\sigma_{\mathrm{T}}\right) \frac{\cos \alpha_{\mathrm{T}}}{\cos \beta_{\mathrm{R} 1}},
$$

where $\beta_{\mathrm{R} 1}$ is the angle of reflection after the transmissive wave $\sigma_{\mathrm{T}}$ experienced the first reflection. In a similar approach, the transmissive wave stress $\sigma_{\mathrm{T} 1}$ in each transmission process can be obtained:

$$
\sigma_{\mathrm{T} 1}=\frac{2 \rho_{1} C_{1}}{\rho_{2} C_{2}+\rho_{1} C_{1}}\left(\Delta \sigma_{1}+\sigma_{\mathrm{T}}\right) \frac{\cos \alpha_{\mathrm{T}}}{\cos \alpha_{\mathrm{T} 1}} .
$$

4.2. Quantification of Stress Attenuation in the Infilled Joint. Equations (6) and (7) indicate that the stress after the stress wave passed through the infilled joint can be quantitatively determined only by calculating $\Delta \sigma_{1}$. The attenuation laws of the stress wave in the propagation process and effective width $r_{r}$ of the infilled joint were combined for a quantitative analysis of $\Delta \sigma_{1}$.

The stress wave attenuation of the general ore-bearing rock media satisfied $\sigma \propto 1 / r_{r}^{\omega}$, where $\omega$ was the attenuation index. For the cylindrical wave in the rock mass, $1 \leq \omega \leq 2$. As the emphasis was laid on investigating the influence of 
TABLE 3: Statistics of energy ratio and energy dissipation of filled joint rock sample.

\begin{tabular}{|c|c|c|c|c|c|c|c|c|c|}
\hline \multirow{2}{*}{$\begin{array}{l}\text { Joint angle } \\
\left({ }^{\circ}\right)\end{array}$} & \multirow{2}{*}{$\begin{array}{l}\text { Joint thickness } \\
(\mathrm{mm})\end{array}$} & \multirow{2}{*}{$\begin{array}{l}\text { Test piece } \\
\text { number }\end{array}$} & \multirow[b]{2}{*}{$W_{\text {I }}(J)$} & \multicolumn{2}{|c|}{$W_{\mathrm{R}} / W_{\mathrm{I}}(\%)$} & \multicolumn{2}{|c|}{$W_{\mathrm{T}} / W_{\mathrm{I}}(\%)$} & \multicolumn{2}{|c|}{$W_{\mathrm{S}} / W_{\mathrm{I}}(\%)$} \\
\hline & & & & $\begin{array}{c}\text { Test } \\
\text { value }\end{array}$ & $\begin{array}{c}\text { Average } \\
\text { value }\end{array}$ & $\begin{array}{c}\text { Test } \\
\text { value }\end{array}$ & $\begin{array}{c}\text { Average } \\
\text { value }\end{array}$ & $\begin{array}{c}\text { Test } \\
\text { value }\end{array}$ & $\begin{array}{c}\text { Average } \\
\text { value }\end{array}$ \\
\hline \multirow{6}{*}{0} & \multirow{3}{*}{4} & СТВB0-1 & 75.21 & 53.13 & \multirow{3}{*}{52.37} & 9.32 & \multirow{3}{*}{11.23} & 37.55 & \multirow{3}{*}{36.40} \\
\hline & & СТВB0-2 & 84.29 & 49.43 & & 11.02 & & 39.55 & \\
\hline & & СТВВ0-3 & 139.45 & 54.56 & & 13.34 & & 32.10 & \\
\hline & & СТНВ0-1 & 70.43 & 58.38 & \multirow{3}{*}{59.59} & 7.78 & \multirow{3}{*}{7.78} & 33.84 & \multirow{3}{*}{32.63} \\
\hline & 10 & СТНВ0-2 & 79.94 & 57.97 & & 8.54 & & 33.49 & \\
\hline & & СТНB0-3 & 130.56 & 62.42 & & 7.01 & & 30.57 & \\
\hline \multirow{6}{*}{30} & \multirow{3}{*}{4} & СТВB0-1 & 72.78 & 49.26 & \multirow{3}{*}{48.36} & 9.32 & \multirow{3}{*}{9.15} & 41.42 & \multirow{3}{*}{42.49} \\
\hline & & СТВB0-2 & 87.34 & 45.38 & & 9.22 & & 45.40 & \\
\hline & & СТВВ0-3 & 123.78 & 50.45 & & 8.90 & & 40.65 & \\
\hline & & СТНВ0-1 & 70.21 & 53.41 & \multirow{3}{*}{56.12} & 6.08 & \multirow{3}{*}{5.89} & 40.51 & \multirow{3}{*}{37.99} \\
\hline & 10 & СТНB0-2 & 81.76 & 55.54 & & 5.57 & & 38.89 & \\
\hline & & СТНВ0-3 & 121.85 & 59.42 & & 6.01 & & 34.57 & \\
\hline \multirow{6}{*}{45} & & СТВB0-1 & 73.21 & 45.67 & \multirow{3}{*}{46.08} & 4.88 & \multirow{3}{*}{4.98} & 49.45 & \multirow{3}{*}{48.94} \\
\hline & 4 & СТВВ0-2 & 80.34 & 40.88 & & 5.13 & & 53.99 & \\
\hline & & СТВB0-3 & 112.47 & 51.69 & & 4.92 & & 43.39 & \\
\hline & & СТНВ0-1 & 68.53 & 49.54 & \multirow{3}{*}{51.16} & 2.14 & \multirow{3}{*}{1.87} & 48.32 & \multirow{3}{*}{46.97} \\
\hline & 10 & СТНВ0-2 & 79.45 & 50.04 & & 1.57 & & 48.39 & \\
\hline & & СТНВ0-3 & 100.56 & 53.90 & & 1.91 & & 44.19 & \\
\hline
\end{tabular}

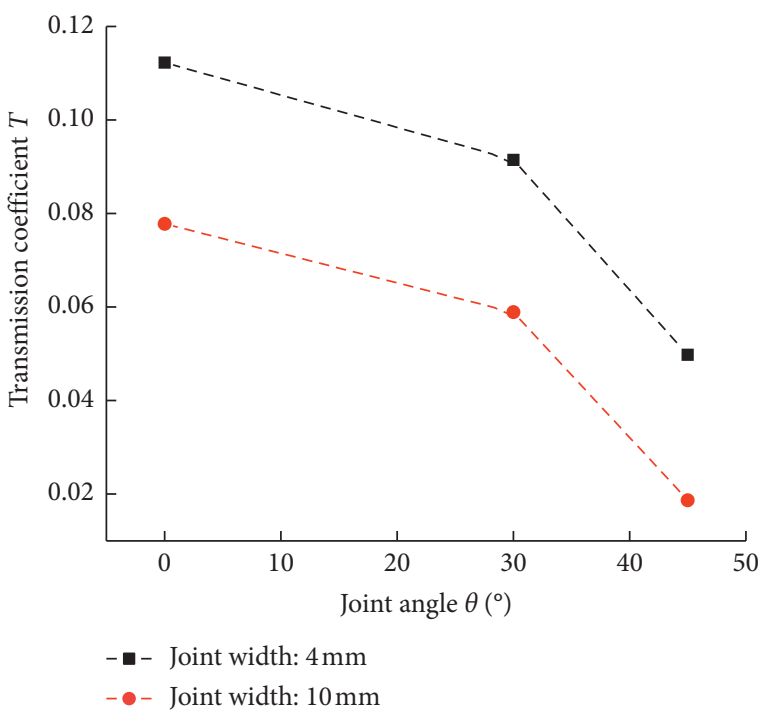

Figure 8: Transmission coefficient curve under different joint angles.

infilled joints on stress wave propagation in this study, it was assumed that the stress wave did not experience attenuation in the hard rock. The joint width $r$ and the attenuation coefficient $\omega$, which were previously defined, were combined to provide the expression of attenuation $\Delta \sigma_{i}$ of the stress wave in the soft intercalated layer, where $\sigma_{\mathrm{R} 0}=\sigma_{\mathrm{T}}$ :

$$
\left.\begin{array}{l}
\Delta \sigma_{i}=\left(1-\frac{k}{r_{r}^{\omega}}\right) \sigma_{\mathrm{R}(i-1)}, \quad i=1,2,3,4, \ldots, n \\
r_{r}=\frac{r}{\cos \theta}
\end{array}\right\}
$$

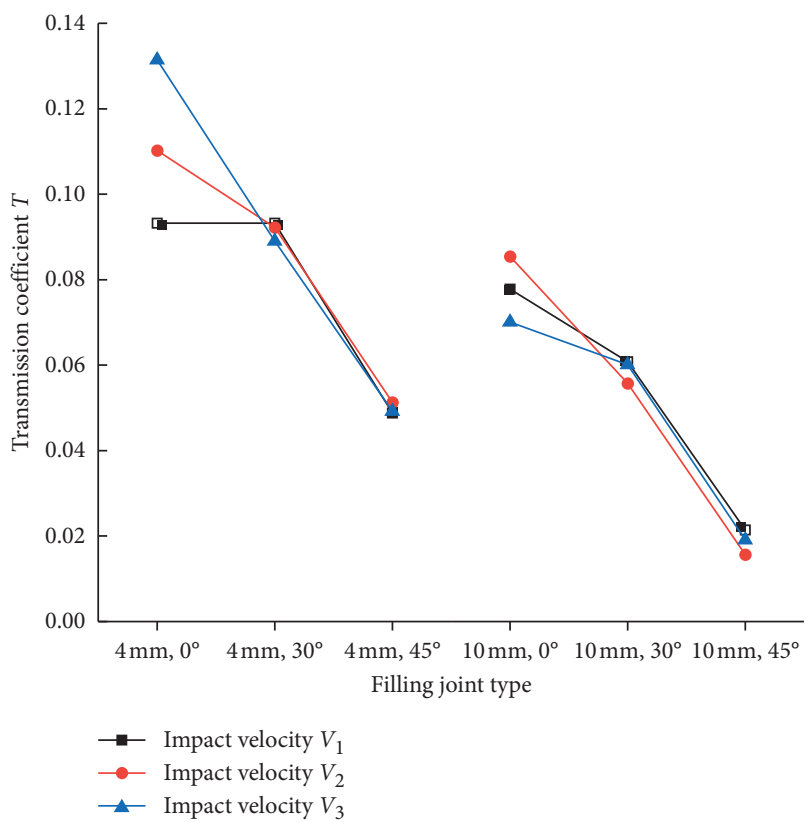

Figure 9: Transmission coefficient variation curve of filling joint types under three impact velocities.

where $k$ is a constant when $i=1$. Meanwhile, the following can be obtained according to Snell's law:

$$
\left\{\begin{array}{l}
\frac{\sin \theta}{C_{1}}=\frac{\sin \beta_{\mathrm{R}}}{C_{1}}=\frac{\sin \alpha_{\mathrm{T}}}{C_{2}}, \\
\frac{\sin \beta_{\mathrm{R}(i-1)}}{C_{2}}=\frac{\sin \beta_{\mathrm{R} i}}{C_{2}}=\frac{\sin \alpha_{\mathrm{T} i}}{C_{1}} .
\end{array}\right.
$$

The first transmission and reflection stresses can be calculated by substituting equations (8) and (9) into equations (6) and (7): 


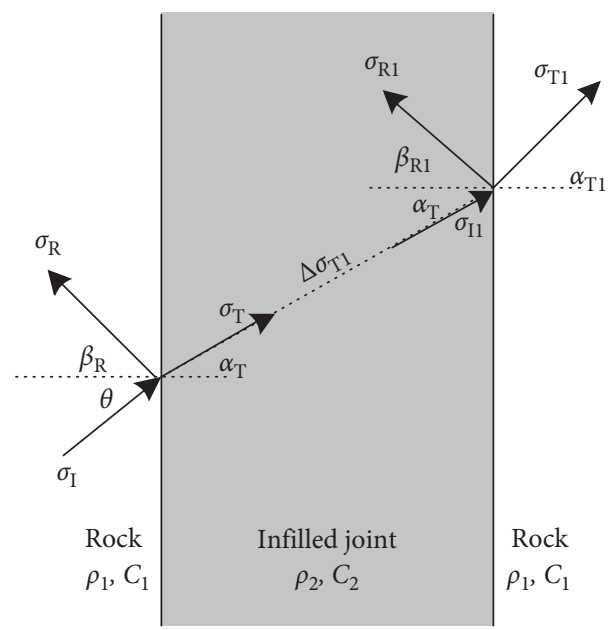

Figure 10: The transfer process of the stress wave in the weak structural plane.

TABLE 4: Stress peak comparison table.

\begin{tabular}{|c|c|c|c|}
\hline \multirow{2}{*}{ Joint angle } & \multirow{2}{*}{ Impact velocity $\left(\mathrm{m} \cdot \mathrm{s}^{-1}\right)$} & \multicolumn{2}{|c|}{ Stress peak $(\mathrm{MPa})$} \\
\hline & & Theoretical value & Experimental value \\
\hline \multirow{3}{*}{0} & 3.30 & 65.95 & 71 \\
\hline & 4.16 & 83.13 & 90 \\
\hline & 5.73 & 114.51 & 120 \\
\hline \multirow{3}{*}{$30^{\circ}$} & 3.57 & 71.34 & 63 \\
\hline & 4.30 & 85.93 & 84 \\
\hline & 5.70 & 113.91 & 110 \\
\hline \multirow{3}{*}{$45^{\circ}$} & 3.25 & 67.74 & 50 \\
\hline & 3.97 & 81.33 & 72 \\
\hline & 5.40 & 114.31 & 106 \\
\hline
\end{tabular}

$$
\left.\begin{array}{l}
\sigma_{\mathrm{R} 1}=\frac{k}{r_{r}^{\omega}} \times \frac{\rho_{1} C_{1}-\rho_{2} C_{2}}{\rho_{2} C_{2}+\rho_{1} C_{1}} \sigma_{\mathrm{T}} \\
\sigma_{\mathrm{T} 1}=\frac{k}{r_{r}^{\omega}} \times \frac{2 \rho_{1} C_{1}}{\rho_{2} C_{2}+\rho_{1} C_{1}} \sigma_{\mathrm{T}} \frac{\cos \alpha_{\mathrm{T}}}{\cos \theta}
\end{array}\right\} .
$$

4.3. Analysis and Discussion. The acquired reflected wave in the test occurred on the rock surface, which differed from the theoretical hypothesis to a certain degree. The transmissive waves passing through the joint were mainly discussed in the experimental and theoretical comparative analyses given that the influence of the infilled joint on stress wave propagation was mainly studied in this paper. The mechanical characteristic parameters of the infilled joint with the oblique incidence of the stress waves are shown in Table 1 . The stress wave propagation velocity $C$ in the different materials can be determined through the following equation [23]:

$$
C=\sqrt{\frac{E}{\rho}} .
$$

The parameters were substituted into equation (11) to obtain the stress wave propagation velocities in the rock and joint materials at 3879 and $3774 \mathrm{~m} / \mathrm{s}$, respectively.
The definition is provided as follows:

$$
T=\frac{\sigma_{\mathrm{T} 1}}{\sigma_{\mathrm{I}}}
$$

where $T$ is the transmissivity coefficient. The related knowledge about the stress wave indicated that the stress of the incident bar can be determined through the following formula:

$$
\sigma_{\mathrm{I}}=\frac{1}{2} \rho_{0} C V
$$

where $\rho_{0}$ is the density of the SHPB, $C$ is the stress wave propagation velocity in the bar, and $V$ is the velocity of the impact bar.

A bullet impacted the incident bar to generate an incident wave, and the specimen was under maximum stress effect when the stress wave reached the interface between the incident bar and specimen. Here, the specimen with $4 \mathrm{~mm}$ thickness of the infilled joint was calculated according to equation (13) for a comparative analysis, as shown in Table 4. As shown in Table 4, under different impact velocities, the theoretical peak stress was largely identical with the peak stress obtained through the test. The three peak stresses increased with the impact velocity but declined as the joint angle increased. 


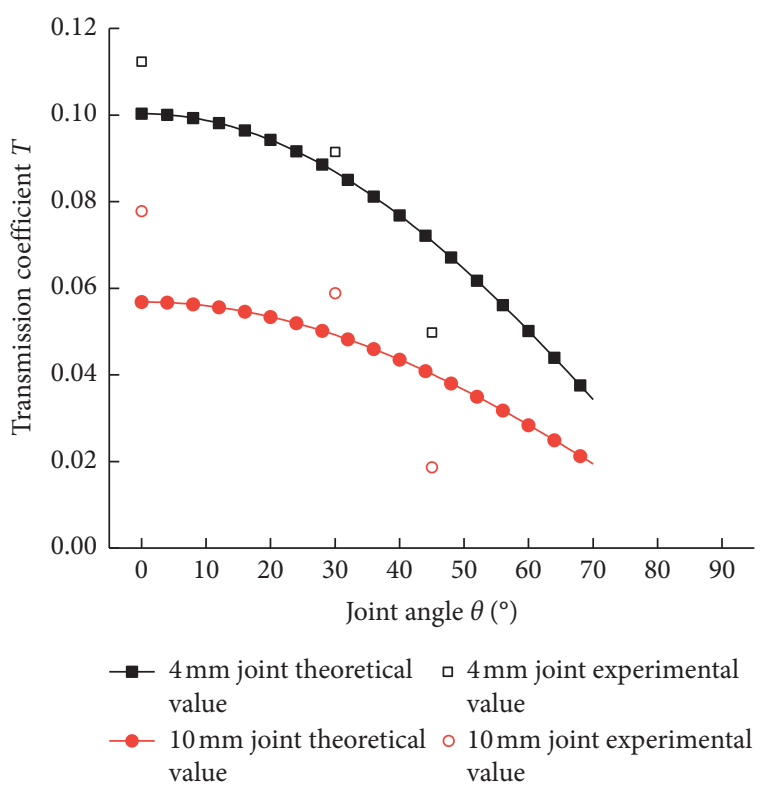

Figure 11: Comparison of transmission energy coefficients between theoretical and experimental values.

The transmissivity coefficient after the stress wave passed through the joint was calculated through equation (12) and compared with the average transmissivity calculated in Table 3. The parameters of the specimens with $4 \mathrm{~mm}$ and $10 \mathrm{~mm}$ thicknesses of infilled joints under $0^{\circ}, 30^{\circ}$, and $45^{\circ}$ conditions were still selected in the calculation process. The concrete results are shown in Figure 11.

Figure 11 shows that because of the existence of infilled joints, the transmission energy coefficients calculated from the theoretical result and that measured by the SHPB test were both very small, even less than 0.12 . The transmission energy coefficient declined as the angle increased. Thus, the larger the joint angle, the poorer the transmission effect of the stress waves, and the more the energy lost in the propagation process. The thickness of the infilled joint material also had a bearing on the transmissivity coefficient. The smaller the joint thickness, the better the transmissivity of the stress waves, and the higher the transmissivity coefficient. In summary, the theoretical calculation result was identical to the test result.

\section{Conclusion}

The SHPB test was carried out for prefabricated infilled jointed rocks with two different thickness values under different angles. They were impacted under three different impact velocities, and the stress expression of the oblique stress wave propagated in the infilled joint was derived. The transmission energy coefficient was defined and calculated and then compared with the test value. The following conclusions can be drawn:

(1) The stress wave propagation in the infilled joint was affected by the impact velocity. The higher the impact velocity, the greater the maximum voltage amplitudes of the incident, reflected, and transmissive waves. In addition, the maximum voltage amplitudes of the incident and reflected waves were greater than that of the transmissive wave.
(2) The failure form and the strength of the jointed rock were closely related to the joint angle. The maximum voltage amplitudes of the three waves presented a declining trend as the joint angle increased. The larger the joint angle, the more evident the declining trend. The joint angle affected the stress-strain curve relation of the infilled jointed rock. Under a highimpact velocity, the failure strength of the rock specimen declined as the joint angle $\theta$ increased. Moreover, the larger the joint angle, the smaller the deformation of the rock specimen.

(3) The change in the transmission coefficient was related to the joint angle. When the joint width was certain, the average transmission coefficient presented a declining trend as the joint angle increased under different impact velocities. In addition, the larger the joint angle, the more evident the declining trend. The large joint angle weakened the influence brought by the joint width to the propagation of the transmissive wave.

(4) Under different impact velocities, the theoretical peak stress was largely identical with the experimental peak stress, and the three peak stresses increased with impact velocity. The strength of the infilled joint material declined as the joint angle increased, thereby indicating that the testing method was accurate and the experimental data results were reliable.

\section{Data Availability}

The datasets used or analyzed during the current study are available from the corresponding author on reasonable request.

\section{Conflicts of Interest}

The authors declare that there are no conflicts of interest regarding the publication of this paper. 


\section{Acknowledgments}

This work was supported by the National Natural Science Foundation of China (Grant nos. 51874144, 51774147, and 51609266).

\section{References}

[1] J. G. Cai and J. Zhao, "Effects of multiple parallel fractures on apparent attenuation of stress waves in rock masses," International Journal of Rock Mechanics and Mining Sciences, vol. 37, no. 4, pp. 661-682, 2000.

[2] L. J. Pyrak-Nolte, "The seismic response of fractures and the interrelations among fracture properties," International Journal of Rock Mechanics and Mining Sciences \& Geomechanics Abstracts, vol. 33, no. 8, pp. 787-802, 1996.

[3] X. Lou, R. Luo, and J. Yu, "Attenuation law of stress waves in cracked rock mass under different confining pressures," Advances in Civil Engineering, vol. 2019, Article ID 7325634, 10 pages, 2019.

[4] X.-Q. Zhou, J. Yu, J.-B. Ye, S.-Y. Liu, R.-G. Liao, and X.-W. Li, "Complex modeling of the effects of blasting on the stability of surrounding rocks and embankment in water-conveyance tunnels," Complexity, vol. 2018, Article ID 4654315, 19 pages, 2018.

[5] B. Indraratna, H. S. Welideniya, and E. T. Brown, "A shear strength model for idealised infilled joints under constant normal stiffness," Géotechnique, vol. 55, no. 3, pp. 215-226, 2005.

[6] B. Indraratna, M. Jayanathan, and E. T. Brown, "Shear strength model for overconsolidated clay-infilled idealised rock joints," Géotechnique, vol. 58, no. 1, pp. 55-65, 2008.

[7] J. Yu, X. Chen, Y.-Y. Cai, and H. Li, "Triaxial test research on mechanical properties and permeability of sandstone with a single joint filled with gypsum," KSCE Journal of Civil Engineering, vol. 20, no. 6, pp. 2243-2252, 2016.

[8] A. Khosravi, A. D. Serej, S. M. Mousavi, and S. M. Haeri, "Effect of hydraulic hysteresis and degree of saturation of infill materials on the behavior of an infilled rock fracture," International Journal of Rock Mechanics and Mining Sciences, vol. 88, pp. 105-114, 2016.

[9] A. Mirzaghorbanali, J. Nemcik, and N. Aziz, "Effects of cyclic loading on the shear behaviour of infilled rock joints under constant normal stiffness conditions," Rock Mechanics and Rock Engineering, vol. 47, no. 4, pp. 1373-1391, 2014.

[10] X. Chen, J. C. LI, M. F. Cai, Y. Zou, and J. Zhao, "Experimental study on wave propagation across a rock joint with rough surface," Rock Mechanics and Rock Engineering, vol. 48, no. 6, pp. 2225-2234, 2015.

[11] X. Chen, J. C. LI, M. F. Cai, Y. Zou, and J. Zhao, "A further study on wave propagation across a single joint with different roughness," Rock Mechanics and Rock Engineering, vol. 49, no. 7, pp. 2701-2709, 2016.

[12] J. C. Li, H. B. Li, G. W. Ma, and J. Zhao, "A time-domain recursive method to analyse transient wave propagation across rock joints," Geophysical Journal International, vol. 188, no. 2, pp. 631-644, 2012.

[13] J. C. Li and G. W. Ma, "Experimental study of stress wave propagation across a filled rock joint," International Journal of Rock Mechanics and Mining Sciences, vol. 46, no. 3, pp. 471478, 2009.

[14] J. Li, G. Ma, and X. Huang, "Analysis of wave propagation through a filled rock joint," Rock Mechanics and Rock Engineering, vol. 43, no. 6, pp. 789-798, 2010.
[15] X. F. Li, H. B. Li, J. C. Li, and J. Zhao, "Effect of joint thickness on seismic response across a filled rock fracture," Géotechnique Letters, vol. 8, no. 3, pp. 190-194, 2018.

[16] Y. Yang, R. S. Yang, J. G. Wang et al., "Simulation material experiment on dynamic mechanical properties of jointed rock affected by joint thickness," Journal of China University of Mining \& Technology, vol. 35, no. 12, pp. 125-131, 2016.

[17] J. Li and G. Ma, "Analysis of blast wave interaction with a rock joint," Rock Mechanics and Rock Engineering, vol. 43, no. 6, pp. 777-787, 2010.

[18] A. Che, H. Yang, B. Wang, and X. Ge, "Wave propagations through jointed rock masses and their effects on the stability of slopes," Engineering Geology, vol. 201, pp. 45-56, 2016.

[19] C. Lin, J. Yu, Y. Y. Cai et al., "Hydro-mechanical coupling test and mesoscopic numerical simulation of sandstone with a single infilled joint," Dyna, vol. 93, pp. 278-285, 2018.

[20] H. Jahanian and M. H. Sadaghiani, "Experimental study on the shear strength of sandy clay infilled regular rough rock joints," Rock Mechanics and Rock Engineering, vol. 48, no. 3, pp. 907-922, 2015.

[21] H. Du, F. Dai, K. Xia, N. Xu, and Y. Xu, "Numerical investigation on the dynamic progressive fracture mechanism of cracked chevron notched semi-circular bend specimens in split Hopkinson pressure bar tests," Engineering Fracture Mechanics, vol. 184, pp. 202-217, 2017.

[22] L. H. Yan, D. Z. Ding, W. X. Sheng et al., "Similar material test study of dynamic failure of jointed rock mass with SHPB," Rock and Soil Mechanics, vol. 35, no. 3, pp. 659-665, 2014, in Chinese.

[23] J. C. Li, W. Wu, H. B. Li, J. B. Zhu, and J. Zhao, "A thin-layer interface model for wave propagation through filled rock joints," Journal of Applied Geophysics, vol. 91, pp. 31-38, 2013. 


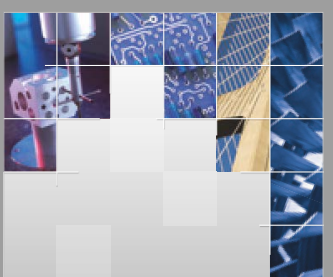

\section{Enfincering}
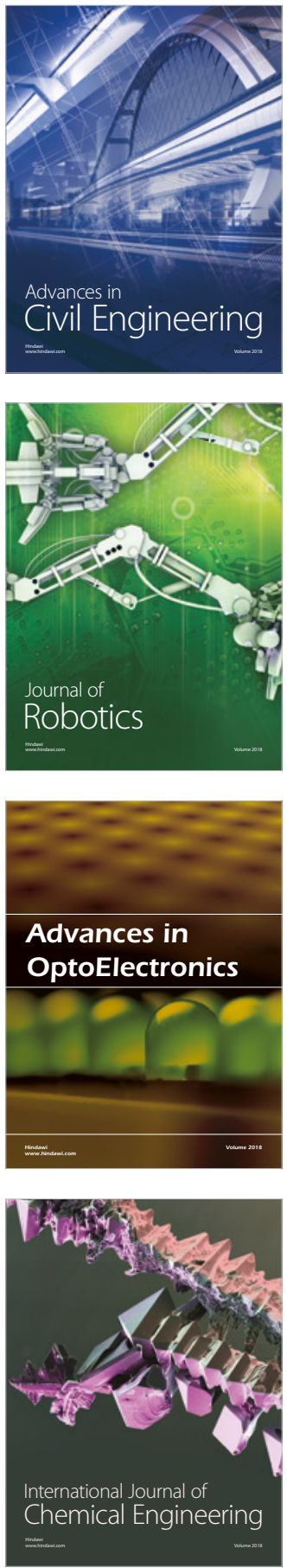

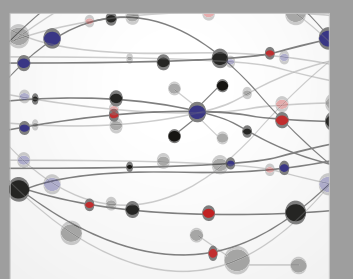

\section{Rotating \\ Machinery}

The Scientific World Journal

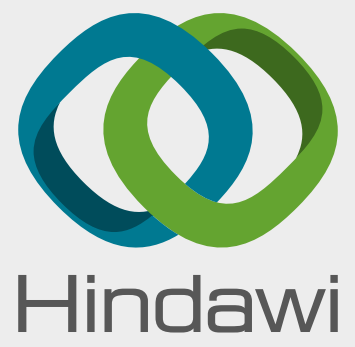

Submit your manuscripts at

www.hindawi.com
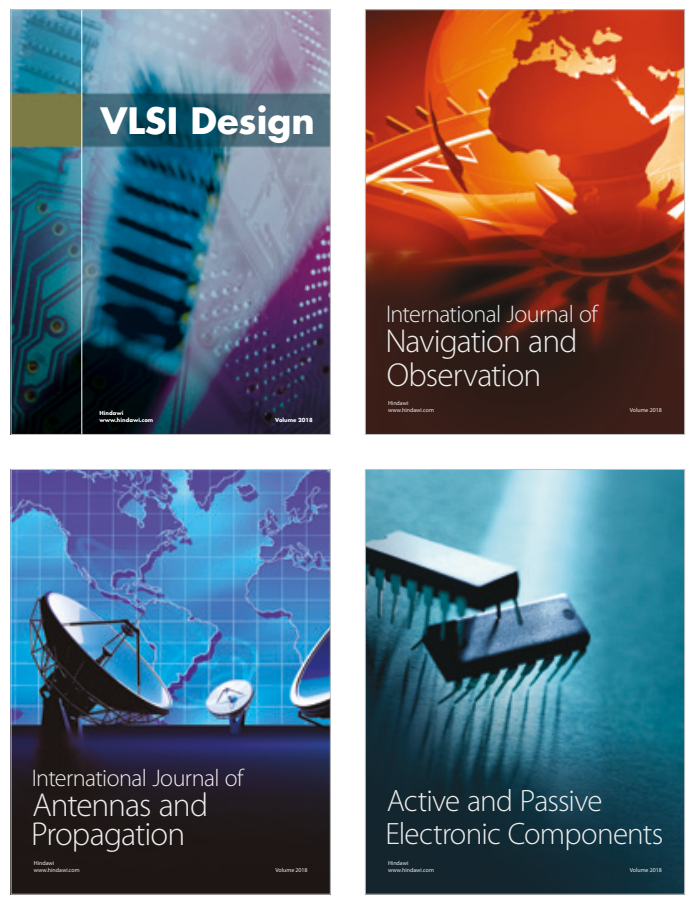
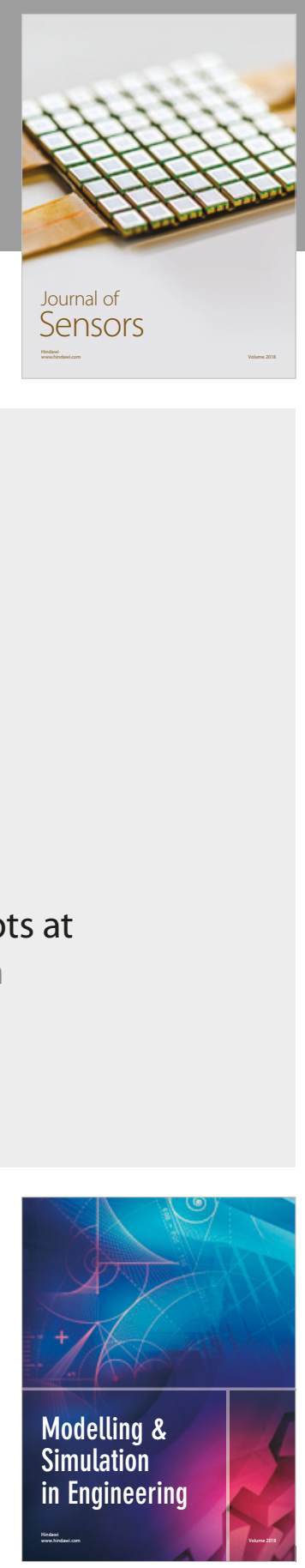

\section{Advances \\ Multimedia}
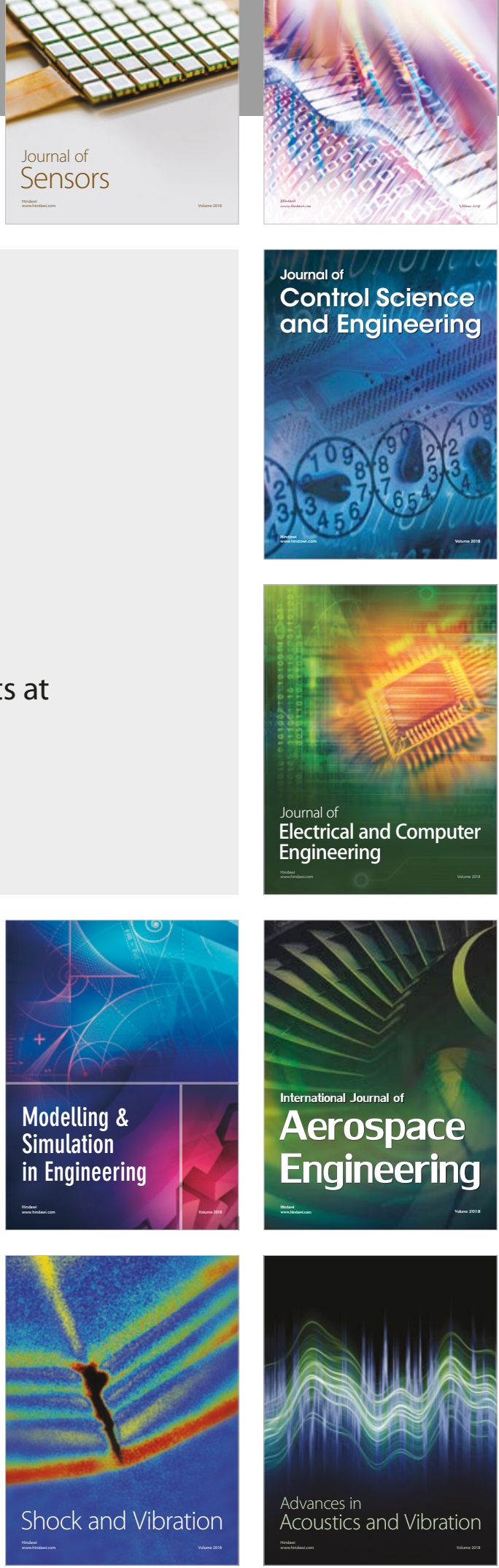